\title{
Theories and Research on Oral Reading Fluency: What Is Needed?
}

\author{
Zainab R. Aldhanhani \\ The British University in Dubai, United Arab Emirates \\ Emad A. S. Abu-Ayyash \\ The British University in Dubai, United Arab Emirates
}

\begin{abstract}
Oral reading fluency skill is considered to be the bridge to reading comprehension. However, it has been neglected in many English reading programs despite the fact that different theories (including behaviorism, information processing model theory, automaticity theory, and Ehri and McCormick's word learning theory) have shed light on this skill. Therefore, the purpose of this study is to review theories, studies and practices relevant to this skill. This study has two aims: (1) to identify the theories underpinning oral reading strategies and (2) to identify the gap in research so far conducted on oral reading fluency. Various reading-aloud techniques and assessment methods are presented in this study. Moreover, some factors that affect students' oral reading fluency are illustrated. Significantly, the practices that this study investigates and presents concerning teaching and assessing oral reading fluency might give an inspiration for the policymakers and curriculum designers to integrate oral reading fluency in their reading programs.
\end{abstract}

Index Terms - oral reading fluency, theories, reading-aloud instructions, assessment methods, factors affecting oral reading fluency.

\section{INTRODUCTION}

Oral reading fluency is a key skill, which is a prerequisite for comprehension as emphasized by Tindal et al. (2016) and Rasinski (2014). They believe that fluency as a skill feeds into comprehension, which is the ultimate goal of reading. According to DiSalle and Rasinski (2017), 90\% of comprehension problems are due to the deficiency in oral fluency. Thus, students who have poor reading fluency in their early stage of academic life will likely have problems in later academic stages. For this reason, it is essential to build and develop literacy skills in the early learning stage (Rasinski 2014). However, this has been neglected in many English learning programmes in various countries.

Investigating oral reading fluency theoretically and through the literature is essential for proposing instructions and implications. In response, this study provides an overview of the instructional reading strategies for oral reading fluency and the assessment techniques employed in the literature. It also provides details about the factors that affect students' oral reading fluency. It would be fair to say that all of the existing studies relating to oral reading fluency have investigated the effects of one or two oral reading-aloud strategies on students' oral fluency. Some of them have examined and discussed one assessment measure whilst others have investigated one or more factors that affect students' oral reading fluency. It is evident that there is presently no research covering the areas which this study aims to investigate. Furthermore, no studies have been found to suggest or provide a comprehensive model that builds and supports oral reading fluency. Hence, this study has clearly addressed a gap in the literature concerning different issues relating to oral reading fluency and would therefore, most certainly add value to the growing literature in oral reading fluency by presenting the issue as comprehensively as possible. In light of this, the objectives of the present paper are:

a) to identify the theories underpinning oral reading strategies

b) to identify the gap in research so far conducted on oral reading fluency with the aim of recommending areas for future studies.

Defining oral reading fluency has been a key issue for many educators and scholars alike. The reason for this is that oral reading fluency involves identifying a host of different aspects in a fixed time, such as the number of: correct words, incorrect words, pauses, repetition of words or phrases and finally mean length of utterance (Rasinski 2014). However, based on current research perspectives, there is a common definition for oral reading fluency, which is the ability to read aloud a text accurately with natural speed (Rasinski 2009; DiSalle \& Rasinski 2017; Samuels 2007). Hence, it is necessary to highlight that Padak and Rasinski (2008) and Samuels (2007) identified three main components of oral reading fluency which are accuracy, automaticity, and prosody. Defining these three terms is imperative to understanding how oral reading fluency should be addressed.

Accuracy is the ability to decode words precisely. First and foremost, for fluent readers to read accurately, they must identify individual words. This identification requires learning the alphabetic principle, which involves letters (graphemes) and sounds (phonemes). In addition, decoding isolated words, such as sight words, high-frequency words, 
and irregular words is paramount. Mastering the previous knowledge allows accurate word identification, which happens instantaneously (Rasinski 2014).

Automaticity, on the other hand, refers to recognising and decoding words effortlessly (Rasinski 2014; Samuels 2007). It depends on the students' knowledge of alphabetic principles and vocabulary (Ehri \& McCormick 1998). Reading becomes automatic once readers master accuracy. Therefore, automaticity and accuracy are closely related. It is proven that readers' cognitive load is reduced as automaticity and accuracy are increased (Samuels 1974). Consequently, the cognitive resources will be devoted to comprehension. It is also believed that the more errors students make in reading accuracy, the less textual information they grasp (Lahmann, Steinkrauss \& Schmid 2017). Hence, both accuracy and automaticity enhance effective reading comprehension. It is also reported that automaticity or accuracy alone is not sufficient to determine students' oral reading fluency (Rasinski 2014). For instance, students might read separate words accurately and rapidly. However, when they read a connected text, they might find it difficult to read at the same level of accuracy and speed. Moreover, reading too quickly might not allow students to comprehend (Rasinski, Rikli, \& Johnston 2009). In fact, to reach a proper level of text comprehension, students should have accurate word recognition (Samuels 2007).

The last component of fluency is prosody, which refers to reading smoothly with expression and intonation that presents the meaning and comprehension of connected text (Rasinski, Rikli, \& Johnston 2009). In some studies, prosody is called expression. Prosody involves reading with the pitch, tone, volume, and rhythm. It also includes chunking words or phrases together and emphasising certain phrases (Padak \& Rasinski 2008). Numerous studies have proven that reading orally with expression helps the reader to build and develop his/her own comprehension skills, the meaning of the text, and speaking skills (Rasinski, Rikli, \& Johnston 2009). Moreover, though a positive relationship between prosody and comprehension was reported in those studies as mentioned earlier, the reliability data for measuring students' prosody was an issue. In fact, there is no valid and reliable measure created yet to measure students' prosody (Haskins \& Aleccia 2014; Sarris \& Dimakos 2015). On the other hand, there are some available valid and reliable measures for both accuracy and automaticity (Rasinski 2004).

\section{THEORIES AND ORAL READING FLUENCY}

Various theories shed light on reading fluency particularly reading-aloud strategies which are behaviourism, information processing model theory, automaticity theory, and Ehri and McCormick word learning theory. The following sections present theories views on building oral reading fluency and instructional implication for each theory.

\section{A. Behaviourism}

Behaviourism is a well-known theory that focuses on the changing of behaviour over a period of time. For behaviourists, information is transferred and conveyed from a knowledgeable person, teacher, to a less knowledgeable source, student (Zuriff 1985). In education, behaviourism can inform literacy instructions meaningfully by leading teachers to use specific strategies and assessment methods. In essence, it is an important theory that is associated with direct instructions and implications for reading that could improve the students' achievement (Tracey \& Morrow 2012). Generally, three basic behavioural theories contribute to behaviourism; classical conditioning, connectionism, and operant conditioning. These three theories focus on breaking down the complex task, in this case reading, into smaller components. For instance, Tracey and Morrow (2012) claimed that reading components are categorised into five categories, which are visual discrimination, auditory discrimination, left-to-right progression during reading, vocabulary and finally, comprehension. These components have some sub-skills. For example, for auditory discrimination, there are sub-skills including phonics, sight words, and blending. Each one of these sub-skills requires a response and feedback. To elaborate, a teacher asks a student to pronounce a word. If the student does it correctly, then the teacher needs to give quick feedback. However, if the student pronounces the word incorrectly, the teacher should correct the student's pronunciation. This can happen by providing sufficient opportunities to pronounce the word repeatedly until the student has perfected it. This is strongly related to oral reading fluency whereby feedback is a requirement to help students improve their reading fluency. It is also emphasised by Rasinski (2014), Padak and Rasinski (2008) and Rasinski and Padak (2000). They believed and insisted on the significance of providing students with appropriate guidance and feedback to help them build their reading fluency. Furthermore, the role of feedback in teaching and assessing reading fluency was stressed by many other researchers (Cummings, Park \& Schaper 2013; Dewey et al. 2015).

Significantly, guided reading, direct instruction, practice, and the repeated reading approaches for LaBerge and Samuels (1974) are examples of the most influential reading strategies that are emphasised by a behaviourism perspective (Tracey \& Morrow 2012). Usually, the guided reading strategy is used more with younger students: kindergarten to grade two levels. For direct instruction, the teacher knows the sub-skills that students need to develop. Therefore, the teacher is responsible for the students' learning by finding out their strengths and weaknesses. Then, the teacher can start teaching and building learners' reading sub-skills directly and explicitly to students as phonics, sight words, high-frequency words and blending words. The teacher has to provide students with lots of practice to acquire the previous sub-skills. This is also stressed by Padak and Rasinski (2008). Padak and Rasinski clearly stated that to start teaching the basic reading skills at an early level is essential to building a good foundation for reading skills. Al- 
Kharusi (2014) claimed that using direct instructions and practice helped students greatly to increase their potential reading fluency. It is important to note that teachers' knowledge is potentially important to building students' reading skills. As stated previously, behaviourists believe that information is transferred from a knowledgeable person to a less knowledgeable source. Moreover, the behaviourism theory focuses on measuring the change in behaviour objectively. With respect to oral reading fluency, students must be assessed on reading skills, such as phonics, fluency, and comprehension. It is the teacher's job to set measurable behavioural objectives to assess students.

Although the behaviourism theory points at different reading-aloud methods and the role of feedback, it is criticized harshly. For example, behaviourism views the learner, reader, as a passive recipient of information in the text. Readers' knowledge and experience do not matter in this theory. Readers are only responding to stimuli. Only perceptual information and the decoding process are significant to this theory. Needless to mention that behaviourists place great attention on the final product or the output, regardless of the processes in learners' brains. Therefore, behaviourism is criticised harshly for this issue. Behaviourism also receives tough criticism because it does not explain how the mind interferes in the processing of information. As a response to the previous shortcomings, there was a major shift towards a cognitive sciences paradigm.

\section{B. Information Processing Model Theory}

In the cognitive science paradigm, scientists and psycholinguists began to focus on how a language could be built and developed in students' brains. One of the cognitive processing models is called the "information processing model". Based on the information processing model (Slavin 2002), oral reading fluency is addressed through various systems that lead readers to engage in specific skills, such as recognising letters and sounds rapidly and retrieving knowledge that is stored in the long-term memory. The brain has a specific capacity for daily tasks. If the students use a significant portion of this capacity and amount of time to read and decode words, then a small capacity and less time will be left and devoted to meaning and comprehension. Thus, if the students learn to read fluently at an early stage, then a big portion of the brain's capacity will be devoted to making sense of the meaning of the text.

This model has three types of memories: sensory memory, short-term memory, which is also called working memory, and long-term memory. When readers see pictures or printed words in a text their sensory memory retains the data. When they read, the information is stored in the short-term memory for thirty-seconds approximately. Certainly, information cannot stay too long in the short-term memory, which has a limited capacity for information. Readers forget the information quickly if they do not encode by rehearsing the information. If they rehearse, in this case, they read aloud many times, information will move into the long-term memory, which has an unlimited capacity over a long period of time. Therefore, teachers have to help students improve their memories by motivating and allowing them to practice to encode data into their long-term memory. This theory promotes reading practice, repeated reading, assisted reading, and rhyming methods as a way to encode data, in this case, recognition of letters, sounds, sight words, and high-frequency words.

Unfortunately, this model as the behaviourism theory has received some criticism. For example, this model views the human mind like a computer or machine, which processes information. Readers receive input or information, i.e. a text. Then, they process the text by reading it and finally, they deliver the output or behavioural response, which the behaviourism theory focuses on. Although this model believes that humans are like computers, it stresses on the three types of memory and how to address any issue considering them, which is clarified earlier. It also tells us that older children have a greater capacity in working memory (Slavin 2002). Therefore, building oral reading fluency should begin at an early level.

\section{Automaticity Theory}

Automaticity theory is a famous theory in the reading fluency field (Samuels 2007) that focuses highly on word recognition. For the automaticity theory, reading fluency is identified as the ability to decode and comprehend a text at the same time (Samuels 2007). As pointed by Tracey and Morrow (2012), reading text has many sub-skills (or processes) such as recognising letters, associating sounds with the letters, blending, segmenting, chunking, skimming, and scanning. However, there are three basic processes that all readers go through during the reading of a text, which are decoding, comprehension, and attention (Samuels 2007; Tracey \& Morrow, 2012). Interestingly, the last one, attention, refers to how much focus and energy readers give to a text when they process the information for comprehension. The more attention one gives to decoding, the less attention one gives to comprehension. Therefore, Samuels (1974) designed a repeated reading strategy based on the automaticity theory. The repeated reading strategy helps students in reducing the capacity for attention and cognition given to decoding a text. Accordingly, the capacity allocated for attention and cognition for higher level processes, such as reading comprehension, will be increased. Fig 1 represents the role of automaticity theory in the working memory of both fluent and less fluent readers. 


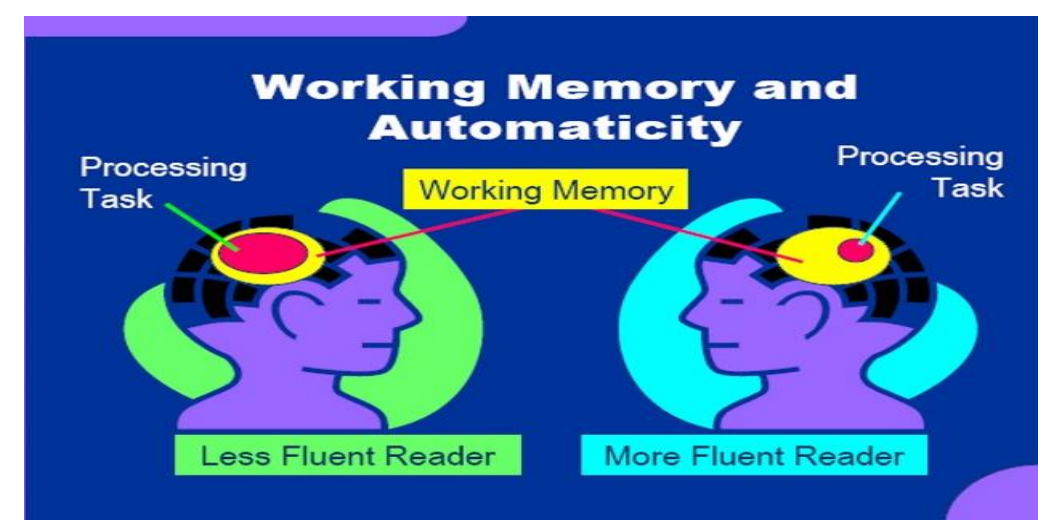

Figure1: The role of automaticity theory in working memory of both fluent and less fluent readers (Adams 2012)

LaBerge and Samuels (1974) theory of automaticity is a bottom-up serial stage model of reading. This means that readers should master the lower level processes to reach to the higher level processes. To certify that, LaBerge and Samuels (1974) believed that teachers should ensure that students recognise all the letters in the early stage of reading through repeated reading. Then, the students can focus on the sounds that the letters make, which are developed later at the blending stage. Teachers can use repeated reading, readers theatre, paired reading, choral reading, modeling reading and assisted reading by recorded audio texts approaches in teaching reading fluency. Significantly, the roles of drilling, repetition, and error correction are vital in the previous approaches. In fact, the key to all these approaches is practice, which improves the speed of reading.

Evidently, the automaticity theory helps to find those who have problems in reading speed (Pikulski \& Chard 2005). The automaticity theory does not believe that readers have a deficit in memory. It is about a lack of attention given to texts. To fix this issue of lacking attention, the automaticity theory promotes using easier texts as a remedy with students, which would help them develop their automatic reading (Samuels 1979). Moreover, Samuels recommended that teachers should use a rubric to evaluate students' reading progress. Using self-assessment and peer assessment techniques is also endorsed by this theory to help students discovering their own strengths and weaknesses.

Similar to the previous theories mentioned, this theory has received negative criticism due to the insufficient explanation. For instance, this theory does not shed light or explain how prosody, a significant component of oral reading fluency (Samuels 2007), can be improved. Therefore, it is criticised for neglecting prosody. Also, though this theory encourages teachers to use easier texts with struggling readers, it does not discuss the readability and the suitability of texts for certain levels. Finally, since this method relies on practice and drilling, therefore, it takes a lot of class time to ensure students' success. However, usually teachers are tied to the course syllabus to deliver on time. Therefore, it is not practical for many teachers.

\section{Ehri and McCormick Word Learning Theory}

Ehri (1995) word learning theory is another widely recognised theory in the field of reading fluency. Her theory presents the reading stages that students go through to achieve reading fluency. Ehri (1995) identified four stages for the development of reading words, which are pre-alphabetic (preschool), partial-alphabetic (kindergarten), full-alphabetic (first grade), and consolidated-alphabetic (second grade). However, later Ehri and McCormick (1998) identified one more phase, which is automatic-alphabetic (beyond second grade). Each of these stages has its own characteristics, which are used to develop instructional implications for students to read words fluently. They guide teachers in their reading instructions and inform their practices. For example, in the pre-alphabetic phase, the teacher has to focus on letter recognition and phonics awareness. In the partial-alphabetic stage, the teacher should model to students how to blend sounds in words. In the third phase, full-alphabetic, students re-read the text multiple times and practice pronouncing various sounds to encode them. Clearly, the first three phases focus on building knowledge of letters, sounds, graphemes, phonemes, and phonics. Concerning reading-aloud strategies, they are used more in the consolidated-alphabetic phase to move students to the advanced stage. It is worth noting that during the automaticalphabetic phase, students develop automaticity and speed in reading familiar and unfamiliar words (Ehri 2005).

Ehri (2002) and Ehri and McCormick (1998) highlighted different aspects of reading fluency. For example, concerning reading instruction, they promoted using various reading methods that provide precise instructions that suit each student's level such as assisted reading, modeled reading and repeated reading approaches (Pikulski \& Chard 2005). The reading instructions must also encourage continuous reading practice to increase students' knowledge of alphabets and sight/high-frequency words. For the assessment of oral reading fluency, Ehri (2002) believed that students should be assessed regularly by observing and giving them the support they need to move from one stage to another (Ehri 2002; Pikulski \& Chard 2005). Furthermore, considering that factors that can affect students' progress in oral reading fluency, Ehri pointed out that having knowledgeable teachers is critical to build a strong foundation of literacy skills. Students, who have problems moving from one stage to another, need knowledgeable teachers, who can support the success of building and developing their reading skills. Ehri also claimed that classroom environment with 
printed words is significant to improve students' vocabulary knowledge (Cardoso-Martins, Rodrigues \& Ehri 2003). Truthfully, Ehri (2002) has made a considerable contribution to the reading field. A plethora of research has considered her theory in their research because they believe that Ehri's reading theory represents a comprehensive coherence framework for teaching how to read effortlessly and fluently (Lahmann, Steinkrauss \& Schmid 2017; Pikulski \& Chard 2005; Rasinski 2014).

\section{ORAL READING FLUENCY STRATEGIES}

The following sections provide a brief description of some of the highly effective reading strategies that involved the reading-aloud approach used in different classroom levels and showed a positive impact on students' oral reading fluency.

\section{A. Repeated Reading}

There has been widespread agreement that the repeated reading approach is the most frequent method used to develop and improve students' reading fluency (Al-Kharusi 2014; Berg \& Lyke 2012; Rasinski 2014; Rubin 2016; Samuels 1979). In fact, studies on oral reading fluency are dominated by research on repeated reading. It is found to be highly effective as it is promoted by many scholars and popular educators in the reading fluency field such as Rasinski (2014) and Samuels (1979). The essence behind this technique is that it increases accuracy, word recognition (sight words), and speed (Samuels 1979). However, this strategy cannot be used with first graders, who have not yet developed knowledge of the alphabet and sounds fully (Ehri 2002; Pikulski \& Chard 2005).

\section{B. Reading Practice}

It is well known that practice makes perfect, and, therefore, the more someone reads, the better reader he/she will become (Rasinski 2014). Reading practice is not about practicing reading the same text as in repeated reading. It is about reading more variety of texts. Therefore, teachers need to encourage students to read not only in school, but also after school (Wallot, Van Rooij \& Hollis 2013). Repeated reading is essential to those, who have difficulties in fluency, but for others allowing them to practice reading different texts is significant not only for students' fluency, but also for their knowledge (Rasinski 2009; DiSalle \& Rasinski 2017).

\section{Modeling}

Plenty of studies have found that modeling is a vital approach to improve students' fluency (Calo, Woolard-Ferguson, \& Koitz 2013; Rasinski 2009). Students might not recognise what it means to be fluent readers. They think that reading fluently means to read rapidly, which is not right because reading speed indicates only the automaticity (Rasinski 2014). Therefore, students need to listen to a fluent, expressive reading by fluent readers. This method increases students' phonological awareness and helps them to understand the meaning of texts (Berg \& Lyke 2012).

\section{Assisted Reading}

Research into fluency has proved that assisted reading improves students' oral reading fluency (Rasinski \& Padak 2000). In this strategy, the reader gets an opportunity to read a text while listening simultaneously to a fluent reading of the same text (Meeks \& Austin 2003). This method helps the readers to decode words successfully, which later helps them in word recognition and automaticity. Also, assisted reading presents to the reader how to read with expression. This strategy can be validated in different forms. For instance, the teacher reads to the whole class. Pre-recorded or audio texts can also be used in which students read a text while listening to them. Another form is that a fluent partner (who is also called a reading coach) reads to students inside and outside the classroom (Rasinski \& Padak 2000). Teachers can implement this strategy with the entire class or with specific students who are non-fluent readers.

\section{E. Rhyming Poetry}

Rasinski et al. (2016) suggested the rhyming poetry strategy for improving students' oral reading fluency through enhancing their phonological awareness. In fact, poetry has been found to be effective for developing students' phonics through learning about common orthographic patterns, word families, and phonograms. Integrating a rhyming poetry approach in the classroom motivates students to learn and explore the language in a relaxed, joyful way (Flores-Saldana 2016). Similarly, reading song lyrics is a powerful method to increase and enhance students' phonological awareness (Patel \& Laud 2007).

\section{F. Readers Theatre}

Black (2016) and Young and Rasinski (2009) emphasised another approach called the "reading theatre or readers theatre approach" to improve students' reading fluency. In this activity, students read a particular script or scenario, poem or play, many times to act it out in front of an audience. Students can rehearse independently or with the guidance of teachers, who model the reading to students until they are able to perform fluently and expressively. Usually, this activity is performed by two or more students. It can be formal or informal. Remarkably, the reading theatre approach involved repeated reading, modeling, and practice which help students in achieving oral reading fluency (Black 2016; Faatz 2009; Sovitsky 2009). 


\section{G. Choral Reading}

Choral reading is also called unison reading. During the implementation of this strategy, the teacher expressively reads aloud a short text, poem or speech to the students and they have to follow the text that the teacher reads. Subsequently, a group of three or more students read in unison the text assigned by the teacher (Moskal \& Blachowicz 2006; Rowen et al. 2015). Also, the entire class can participate in the activity and read along with or without the teacher. This "reading along" procedure has been shown to increase students' confidence and enjoyment in reading because it reduces their shyness and panic of making mistakes when they read aloud independently. Furthermore, it helps students feel successful as readers (Rowen et al. 2015). Notably, this method involves modeling, practice, and repeated reading.

\section{H. Paired Reading}

Paired reading is a simple research-based reading strategy that is used to boost reading fluency and accuracy at different grades (Padak \& Rasinski 2008). It is also called a partner reading approach. Every student benefits from this strategy, not only struggling readers or those diagnosed with dyslexia (Schneider 2007; Topping 2014). The paired reading approach is used to improve students' listening and speaking skills, as well as, their motivation to read (Padak \& Rasinski 2008; Topping 2014). Students work together independently under the supervision of teachers. In this strategy, two students read aloud to each other a sentence, or a paragraph, which depends on both text and students' levels. Usually, one of the students is less fluent or less confident in reading aloud alone than his/her partner. It is no surprise that the paired reading strategy is an ideal way to increase students' confidence and self-esteem (Berg \& Lyke 2012).

\section{ORAL ReAding FluenCy AsSESSMENT}

It is important to measure fluency in a reliable way that helps examiners, teachers, and practitioners to easily distinguish between fluent and non-fluent readers (Rasinski 2004; Tindal et al. 2016). A comprehensive reading programme should integrate reading assessments that measure students' skills at the beginning, throughout, and at the end of the reading programme. The importance behind assessing students' oral reading fluency is to help teachers to determine the fluency instruction that works best for students' needs and abilities. Also, assessing students informs teachers and directs them to make new decisions about creating, modifying or integrating new fluency approaches to stimulate students' interests and motivation to read. Additionally, reading assessments provide teachers with information about the skills that students have and have not achieved. The assessments inform teachers about the students' levels too. Teachers, then, can monitor students' progress and performance and move them to the next level. Accordingly, the assessment of oral reading fluency should start early during the academic year through the teacher's observation.

There are three fundamental aspects of oral reading fluency that need to be assessed; accuracy, automaticity, and prosody. The assessment of fluency should reflect the previous aspects, which also includes assessing; (1) numbers of syllables, (2) speech rate, (3) mean length of runs, (4) the frequency of silent and filled pauses, (5) tone in reading, (6) smooth delivery of phrases, (7) communicating meaning through speeding up or slowing down, and finally (8) pace of reading (Al-Kharusi 2014; Rubin 2016). In fact, due to those multiple aspects of fluency, the assessment of oral reading fluency has been neglected, in particular, the assessment of prosody (Rasinski 2004; Samuels 2007; Tindal et al. 2016).

There are various tools and tests available to measure oral reading fluency. Those tools have almost the same procedure for evaluating students' oral reading performance. Students have to read aloud a passage or a list of words over a period of time. Based on the consulted literature (Thornblad \& Christ 2014), the most popular and widely used assessments in the literature are Curriculum-Based Measurements (CBMs) and Dynamic Indicators of Basic Early Literacy Skills (DIBLES). However, observations, field notes, and rubrics are important tools to assess students. The following sections discuss the previous tools.

CBM is a set of tests for measuring students' academic skills in math, reading, writing, and spelling. Based on research, it has good reliability and validity (Thornblad \& Christ 2014). CBM in reading has two types of measures that are drawn from the curriculum. For the first measure, which is called the maze task, students read a passage aloud or silently for three minutes. The students have to select one of three words to replace the missing word so that it restores meaning to the text (Cummings, Park \& Schaper 2013). Basically, it is used to measure understanding and comprehension. In the second type, students read a passage aloud for one minute. The number of correct words is used as the index for CBM passage reading. This task is easy to administer and score, which is known as oral reading fluency or ORF. It is conducted at regular intervals and started from first grade through eighth grade (Thornblad \& Christ 2014).

DIBLES is designed to measure students' acquisition of early literacy skills (Dewey et al. 2015). It is designed based on curriculum measurement too. It evaluates students' progress and provides feedback on the best instructional objectives and outcomes to speed up and enhance students' development (Dewey et al. 2015; Samuels 2007). DIBLES Oral Reading Fluency (ORF) is a standardized test that is developed by the University of Oregon and that measures students' accuracy, speed, and automaticity. It is administered to students individually starting mid-first grade through sixth grade (Cummings, Park \& Schaper 2013). It has specific criteria to evaluate students. It also has a risk levels chart that illustrates the number of words that students need to read for one minute by the end of each grade. It is worth mentioning that this test is administered three times in a year; autumn, winter, and spring. For this reason, it takes up a 
large amount of the classroom time, six-minutes per student, which teachers find to be overwhelming (Rasinski 2009; Rasinski 2004; Rasinski \& Padak 2005).

DIBELS ORF is almost identical to the CBM ORF. There is no significant difference between them. In those two assessments, Reading Assessment Passages (RAPs) are being used which are field-tested and validated (Hudson, Lane \& Pullen 2005). RAPs are designed based on the curriculum measurement to assist the teachers in their instructional strategies and monitor the student's development and performance. Both CBM ORF and DIBELS ORF measure five areas; initial sound fluency, letter naming fluency, phoneme segmentation fluency, nonsense word fluency, and oral reading fluency (Dewey et al. 2015; Samuels 2007). The score of those oral reading fluency assessments, which are a one-minute timed reading of a text is called Words-Correct Per-Minute (WCPM). The WCPM score is compared to certain norms and benchmarks to determine the student's level if it is, for example, above the benchmark, at the expected benchmark, below the benchmark, or significantly below the benchmark (Rasinski \& Padak 2005).

Observations, field notes, and rubrics are recommended to employ before using the previous assessments to assess oral reading fluency (Rasinski 2004). There is very little doubt that the teacher's observation is the first main resource to measure students' fluency. It helps teachers to assess students' progress early. Before starting any formal assessments, the teachers can diagnose students informally by observing them during class time. Teachers can observe students' speed, pauses, mispronounced words, and expression. Furthermore, taking notes is not less important than observation (Rasinski 2004). After observing students, teachers might take notes on students' performance and keep them to monitor their progress over a year. In relation to using a rubric, many educators recommended using it to assess students' oral reading fluency, particularly prosody (Rasinski, Rikli, \& Johnston 2009). Prosody is associated with readers' understanding of texts. Using a guided rubric that includes evaluation of a reader's voice; rise and fall, expression, and phrasing words in the text is important. Significantly, Rasinski, Rikli, and Johnston (2009) developed fluency scales to determine students' fluency including prosody. The Multidimensional Fluency scale incorporates smoothness, phrasing, and pace to measure students' prosodic reading.

\section{FACTORS AfFeCting ORAL READING FluenCy}

It is well established that studying the factors that affect students' oral reading fluency and their academic reading achievement level is important in order to take action and do something about those factors to help students maximise their reading competencies and skills. However, there are some factors that can be controlled, and other complex factors that cannot be handled by the school, such as the socioeconomic status of the students, ethnicity, gender, and physical disabilities (Hermosa 2002; Limbrick, Madelaine, \& Wheldall 2011; Van Dijk 2018). The following sections highlight the studies which illustrate, reveal and expose some of these factors.

Van Dijk (2018) investigated the influence of students' characteristics on early elementary oral reading fluency including grades one, two and three. It was found that the students' characteristics such as gender and their basic foundation of English skills can affect their oral reading fluency. For gender, the results presented that girls performed better than boys in the ORF test. Also, the students with a good foundation of phonics awareness and word recognition performed better than those, who did not receive a good basis of English literacy skills. This finding is pointed by Rasinski (2014) and Ehri (2002) as discussed earlier in theories.

The role of intrinsic and extrinsic motivation to read and students' attitude towards reading-aloud were another factors reported by Rowen et al. (2015). Usually, students are driven by their extrinsic motivation in which they focus on the grades they need to get. However, students' intrinsic motivation is the most important for them. Therefore, teachers should address students' intrinsic motivation by providing them with a wide range of different texts such as poetry, novels, plays and short stories that would engage and attract their attention and interest. Needless to say that information processing model emphasises on using a wide range of genre to stimulate students' interest.

Cummings, Park, and Schaper (2013) believed that passage effect (level of difficulty) is an important factor that can affect students' oral reading fluency. Their study suggested that the passages should be developed to match students' capabilities and levels. Similarly, Wallot, Van Rooij and Hollis (2013) recommended in their study that the level of a text should be taken into consideration during the assessment of students' reading fluency. It is unfair to use hard text, particularly during students' assessment. Moreover, the genre should be considered during the assessment.

A case study with a few participants, only four, was conducted by Devaney, Foord, and Anne (2012) to investigate the factors that affected four high school English second language learners' (ESL) reading fluency. It was indicated that the students' motivation to read, their anxiety about making mistakes and their peers' comments when the students read in the classroom had an effect on the students' performance. Therefore, the researchers recommended that teachers should motivate the students to read and support them by creating a positive classroom environment and building rapport among students so no one in the class would be afraid of making mistakes. A similar interesting study has been conducted by Tysinger, Tysinger, and Diamanduros (2010). They examined the relationship between social anxiety and students' performance in reading fluency and comprehension. Though it was found that anxiety affected students' reading fluency in Devaney, Foord, and Anne (2012) study, in contrast, Tysinger, Tysinger, and Diamanduros (2010) found that anxiety did not affect students' reading fluency, but it affected students' comprehension. Furthermore, there is a study more recent than the previous two studies about the impact of anxiety, but on the oral narrative speech of students in Iran (Sanaei, Zafarghandi \& Sabet 2015). Interestingly, this study revealed the same findings as the Devaney, 
Foord, and Anne (2012) study. The findings illustrated that classmates commenting on students' oral reading could affect their oral fluency, though the findings were not that significant.

More uncontrolled factors were proposed by Duursma, Augustyn, and Zuckerman (2008). They believed that parental education, students' socioeconomic status, and ethnicity had a great impact on literacy skills including oral reading and speaking skills. Also, the authors highly emphasised the role of parents at home with their children. Students, whose parents read to them at home, seemed to be more fluent. Also, the role of the home environment in which parents encourage their children to read and retell the stories had a positive impact on students' reading-aloud performance. Similarly, Geske and Ozola (2008) investigated the reasons behind the low level of reading literacy among primary school students in fourth grade. They found the same results as in the Duursma, Augustyn, and Zuckerman (2008) research. It is important for parents to read aloud to their children to help them read fluently and comprehend texts easily.

The final study, which was conducted seventeen years ago, identified multiple factors that can affect learner reading which were reported in the above studies (Hermosa 2002). These factors emerge from two main domains, which are psychosocial development (motivation to read, reading interest, readability, reading readiness, emotional problems and family issues), physical and physiological development (mostly health problems: hunger, illness and malnutrition, visual and hearing problems). It is understandable that students with health problems are likely to have academic problems. Thus, more current research studies (Cummings, Park \& Schaper 2013; Piper \& Zuilkowski 2016; Wallot, Van Rooij \& Hollis 2013) tried to understand why many young and adult learners with good health still have some difficulties in reading.

\section{CONCLUSION}

Collectively, the previous studies have outlined and provided different reading-aloud strategies, assessment methods and factors influencing oral reading fluency. With respect to all the reviewed research, it is imperative to note the context and sample size which can affect the outcomes of a study (Creswell 2005). Moreover, the majority of the consulted studies investigated one or two reading-aloud strategies and in most cases used one assessment method. A few studies focused on the factors. For these reasons, further research should address the previous gaps, which would give more insight into this issue.

This study set out to identify the theories underpinning oral reading strategies and the gap in research so far conducted on oral reading fluency. In fact, the findings helped to identify how oral reading fluency should be addressed in any reading program. The conclusion which can be drawn from the present study is that oral reading fluency is a significant skill and component of reading, which should be integrated into any English reading program. The outcomes of this humble research have important implications for building the foundation for teaching and assessing reading fluency in consideration of the factors that have been highlighted.

\section{REFERENCES}

[1] Adams, M. (2012). Fostering fluency via read naturally. https://player.slideplayer.com/12/3551610/data/images/img5.jpg (accessed 17 May 2018).

[2] Al-Kharusi, K. (2014). The effectiveness of repeated reading in reading fluency in English of grade four Omani students. M.A. Thesis. University of Nottingham, Malaysia.

[3] Berg, K., \& Lyke, C. (2012). Using repeated reading as a strategy to improve reading fluency at the elementary level. Distributed by ERIC Clearinghouse.

[4] Black, A. (2016). The effects of reader's theatre on reading comprehension and fluency of fifth-grade students. PhD thesis. Walden University.

[5] Calo, K. M., Woolard-Ferguson, T., \& Koitz, E. (2013). Fluency idol: Using pop culture to engage students and boost fluency skills. The Reading Teacher 66, 454-458.

[6] Creswell, J. (2nd ed.) (2005). Educational research: Planning, conducting and evaluating quantitative and qualitative research. New Jersey: Pearson Education, Inc.

[7] Cummings, K. D., Park, Y., \& Schaper, H. A. B. (2013). Form effects on DIBELS next oral reading fluency progressmonitoring passages. Assessment for Effective Intervention 38, 91-104.

[8] Devaney, K., Foord, K., \& Anne, D. (2012). A case study of four high school ESL students' oral reading fluency and affect. http://cornerstone.lib.mnsu.edu/etds/96 (accessed 22/6/2018).

[9] Dewey, E.N., Powell-Smith, K.A., Good, R.H., Kaminski, R.A. (2015). DIBELS next technical adequacy brief. Eugene, OR; Dynamic Measurement Group, Inc.

[10] Duursma E., Augustyn M., \& Zuckerman B. (2008). Reading aloud to children: The evidence. Archives of Disease in Childhood 93, 554-557.

[11] Ehri, L. (2005). Learning to read words: Theory, findings and issues. Scientific Studies of Reading 9, 167-188.

[12] Ehri, L. (1995). Stages of development in learning to read words by sight. Journal of Research in Reading 18, 116-125.

[13] Ehri, L. (2002). Phases of acquisition in learning to read words and implications for teaching. British Journal of Educational Psychology: Monograph Series 1, 7-28.

[14] Ehri, L., \& McCormick, S. (1998). Phases of word learning: Implications for instructions with delayed and disabled readers. Reading and Writing Quarterly: Overcoming Learning Difficulties 14.2, 135-164. 
[15] Faatz, M. E. (2009). The effects of readers' [sic] theater on the fluency and comprehension of students reading below grade level. Thesis. S.U.N.Y College at Brockport.

[16] Flores-Saldana, M. E. (2016). The positive connection between poetry and reading fluency in kindergarten through sixth grade classrooms. M.A. Thesis. California State University, Stanislaus.

[17] Geske, A. \& Ozola, A. (2008). Factors influencing reading literacy at the primary school level. Problems of Education In The 21st Century 6, 71-77.

[18] Haskins, T. \& Aleccia, V. (2014). Toward a reliable measure of prosody: an investigation of rater consistency. International Journal of Education and Social Science 1, 102-112.

[19] Hermosa, N. (2002). The Psychology of reading, Philippines: UP. Open University

[20] Hudson, R., Lane, H., \& Pullen, P. (2005). Reading fluency assessment and instruction: What, why, and how? The Reading Teacher 58, 702-714.

[21] LaBerge, D., \& Samuels, S. J. (1974). Toward a theory of automatic information processing in reading. Cognitive Psychology 6 , 293-323.

[22] Lahmann, C., Steinkrauss, R., \& Schmid, M. (2017). Speed, breakdown, and repair: An investigation of fluency in long-term second-language speakers of English. International Journal of Bilingualism 21. 2, 229-241.

[23] Limbrick, L., Madelaine, A., \& Wheldall, K. (2011). Gender differences in oral reading fluency: are there implications for identifying low-progress readers? Special Education Perspectives 20, 5-23.

[24] Meeks, L. L., \& Austin, C. J. (2003). Literacy in the secondary English classroom: strategies for teaching the way kids learn. Boston, Allyn and Bacon.

[25] Moskal, M. K., \& Blachowicz, C. (2006). Partnering for fluency. New York: Guilford Press.

[26] Padak, N., \& Rasinski, T. V. (2008). Evidence-based instructions in reading: a professional development guide to fluency. Boston, MA, Pearson/Allyn and Bacon.

[27] Patel, P., \& Laud, L. E. (2007). Using songs to strengthen reading fluency. Teaching Exceptional Children Plus 4, 2, 1-17.

[28] Pikulski, J. \& Chard, D. (2005). Fluency: Bridge between decoding and reading comprehension. Reading Teacher 58, $510-519$.

[29] Piper B., \& Zuilkowski S. (2016). The role of timing in assessing oral reading fluency and comprehension in Kenya. Language Testing 33, 75-98.

[30] Rasinski, T. (2004). Assessing reading fluency. Distributed by ERIC Clearinghouse.

[31] Rasinski, T. (2009). Essential readings on fluency. Newark, Del, International Reading Association.

[32] Rasinski, T. (2014). Fluency matters. International Electronic Journal of Elementary Education 7, 3-12.

[33] DiSalle, K. \& Rasinski, T. (2017). Impact of short-term intense fluency instructions on students' reading achievement: a classroom-based, teacher-initiated research study. Journal of Teacher Action Research 3, 1-13.

[34] Rasinski, T. \& Padak, N. (2000). Effective reading strategies: teaching children who find reading difficult. Upper Saddle River, N.J., Merrill.

[35] Rasinski, T., \& Padak, N. (2005). 3-Minute reading assessments: word recognition, fluency \& comprehension. New York, Scholastic Teaching Resources.

[36] Rasinski, T., Rikli, A., \& Johnston, S. (2009). Reading fluency: More than automaticity? More than a concern for the primary grades? Literacy Research \& Instruction 48, (4), 350-361.

[37] Timothy V. Rasinski, William H. Rupley, David D. Paige, \& William Dee Nichols. (2016). Alternative text types to improve reading fluency for competent to struggling readers. International Journal of Instruction 9, 163-178.

[38] Rowen, D., Biggs, D., Watkins, N., \& Rasinski, T. (2015). Choral reading theater: Bridging accuracy, automaticity, and prosody in reading fluency across an academic unit of study. Journal of Teacher Action Research 1, 53-69.

[39] Rubin, D. I. (2016). Growth in oral reading fluency of Spanish ELL students with learning disabilities. Intervention in School and Clinic 52, 34-38.

[40] Samuels, S. J. (2007). The DIBELS tests: Is speed of barking at print what we mean by reading fluency. Reading Research Quarterly 42.4, 563-566.

[41] Samuels, S. J. (1979). The method of repeated readings. The Reading Teacher 41, 756-760.

[42] Sanaei, O., Zafarghandi, A. M., \& Sabet, M. K. (2015). The effect of classroom anxiety on efl learner's oral narratives fluency: The case of intermediate level students. Theory and Practice in Language Studies 5, 1390-1400.

[43] Sarris, M., \& Dimakos, I. C. (2015). Oral reading fluency and prosody: a preliminary analysis of the Greek language. Themes in Science and Technology Education 8, 47-62.

[44] Slavin, R. E. (2002). Educational psychology: theory and practice. Princeton, N.J., Recording for the Blind \& Dyslexic.

[45] Sovitsky, C. (2009). Read it like you mean it: using reader's theatre to improve oral reading fluency. Davis, Calif, University of California, Davis.

[46] Thornblad, S.C., \& Christ, T.J. (2014). Curriculum-based measurement of reading: Is 6 weeks of daily progress monitoring enough? School Psychology Review 43.1, 19-29.

[47] Tindal, G., Nese, J. F. T., Stevens, J. J., \& Alonzo, J. (2016). Growth on oral reading fluency measures as a function of special education and measurement sufficiency. Remedial and Special Education 37, $28-40$.

[48] Topping, K. J. (2014). Paired reading and related methods for improving fluency. International Electronic Journal of Elementary Education 7, 57-70.

[49] Tracey, D. H., \& Morrow, L. M. (2012). Lenses on reading: an introduction to theories and models. New York, Guilford Press.

[50] Tysinger, J. A., Tysinger, P., \& Diamanduros, T. (2010). The Effect of Anxiety on the Measurement of Reading Fluency and Comprehension. Georgia Educational Researcher 8, 1-15.

[51] Van Dijk, W. (2018). The influence of student characteristics on early elementary oral reading fluency. Journal of Special Education Apprenticeship 7.1, 1-10.

[52] Wallot S., Van Rooij M., \& Hollis G. (2013). Connected text reading and differences in text reading fluency in adult readers. PLOS ONE 8, 1-22. 
[53] Young, C. \& Rasinski, T. (2009). Implementing readers theatre as an approach to classroom fluency instruction. The Reading Teacher 63, 4-13.

[54] Zuriff, G. (1985). Behaviorism: A conceptual reconstruction. New York: Columbia University Press.

Zainab R. Aldhanhani was born in the UAE on February 5, 1985. She got her B.A. in education, majoring in teaching English for elementary level from UAE University, UAE in 2008. In 2014, she got her M.A. in Online curriculum and instruction from HBMS University. In 2019, she graduated from British University in Dubai with a Ph.D. in Education majoring in TESOL.

She has experience in teaching English to young learners for more than 11 years. Her research areas focus on reading fluency, teaching methods, educational technology, curricula development and assessment. She has participated in some international conferences and seminars such as TESOL Arabia, HBMSU conference and ALLT Zayed University conference and presented papers.

Emad A. S. Abu-Ayyash achieved his Ph.D. degree in Education/TESOL from the British University in Dubai, United Arab Emirates in 2016, his M.A. degree in translation from Yarmouk University in Irbid, Jordan in 2007 and his B.A. degree in English literature and linguistics from Yarmouk University in Irbid, Jordan in 1996. He currently holds the position of assistant professor in the faculty of education at the British University in Dubai. He also worked as an Instructional Leadership Coordinator, English lecturer, English Team Leader, English Teacher and Translator. His research interests include discourse analysis, teaching and learning, translation, assessment, and TESOL. 